\title{
EL FACTOR GENERAL DEL REY \\ Y LAS FINANZAS DE LA MONARQUÍA HISPÁNICA
}

CARLOS ÁLVAREZ NOGAL

Universidad Carlos III de Madrid

\section{RESUMEN}

En este artículo se estudia la figura del Factor General del rey dentro de la organización y funcionamiento de la Real Hacienda castellana entre 1627 y 1644, coincidiendo con el gobierno reformista del Conde-duque de Olivares. Durante esos años, el desempeño de este cargo recayó en Bartolomé Spinola, uno de los más importantes hombres de negocios genoveses del reinado de Felipe IV. El estudio aborda cómo se organizó la gestión de los recursos y la toma de decisiones económicas por parte de la Real Hacienda en el siglo XvII y el papel que jugaron en este aspecto algunos hombres de negocios privados. Primero estudiamos qué sentido tuvo la presencia de un Factor General en las finanzas de la Corona. En segundo lugar, explicamos quién era Bartolomé Spinola y cómo se convirtió en un importante hombre de negocios gracias a su actividad como banquero privado. Y por último, analizamos brevemente algunas de las funciones desempeñadas por el Factor General tanto en la financiación de los gastos de la Corona como en los problemas generados por la moneda de cobre.

\section{SUMMARY}

This paper studies the figure of «Factor General del rey» in the organization and work of the Royal Finances of Castilia between 1627 and 1644, under the reformist government of the Count-Duke of Olivares. During these years, the Factor General was Bartolomé Spinola, one of the most importants Genoese bankers of Phillip IV. This article analyses the strategy of Royal Finances in the financial market during the early seventeenth century, and the role played by the most important bankers. To begin with, I examine 
why the Royal Finances needed a Factor General. At this moment, the Crown was establishing a system where the policy was established by experts. The presence of financiers in the court of Madrid grew as much as to influence economic policy. Later afterwards, I explain who Bartolomé Spinola was and how he got to become the main important banker, and then the Factor General. Drawing upon the experience and understanding he gained from his activities in the financial markets as a private banker, he could influence the direction of the political economy of the Spanish Empire. Finally, I analyse briefly some of the functions of the Factor General in the financing of the Crown's expenses, and his intervention in the problems relative to the vellon coinage.

El funcionamiento financiero de la Monarquía Hispánica es uno de los capítulos más apasionantes de la historia económica española y europea gracias a su condición de potencia imperial. Los estudios sobre la Real Hacienda de Castilla realizados hasta ahora nos permiten disfrutar de una visión general de la organización y evolución del sistema impositivo, así como de aspectos relevantes en el funcionamiento de sus finanzas ${ }^{1}$, pero aún quedan muchas sombras por aclarar y muchas preguntas a las que responder.

Este trabajo pretende arrojar luz sobre la organización financiera de la Monarquía Hispánica en el siglo XvI, y más concretamente, sobre sus mecanismos de gestión y toma de decisiones, una cuestión clave para entender las directrices marcadas por la Corona en su política crediticia. Tal y como ha señalado el profesor Ruiz Martín, los «asientos» y «factorías» negociados con los banqueros extranjeros son exponentes típicos de la madurez y agilidad que alcanzó el crédito castellano durante el reinado de los Austrias. Son conocidas desde hace tiempo las principales características del «asiento» ${ }^{2}$, pero sabemos poco sobre lo que supone la «factoría ${ }^{3}$. Quizá porque esta forma de negociación fue minoritaria, pues de hecho, durante los dos siglos que gobernó la dinastía Habsburgo, de los más de mil quinientos créditos negociados sobre los ingresos de los reinos de Castilla las factorías no representaron ni un diez por ciento del total. A pesar de esa menor importancia en términos cuantitativos, creemos que su presencia en la negociación crediticia durante el siglo xvI tuvo

'Domínguez Ortiz (1956) y (1960), Garzón Pareja (1980), Ruiz Martín (1965) y (1970), pp. 1-196, Tinoco Rubiales (1981), pp. 347-350, Artola (1982), pp. 21-73, Hernández Estévez (1983), Sanz Ayán (1988), pp. 27-112, Sánchez Belén (1996), pp. 1-114, Gelabert (1997), pp. 29-126, Álvarez Nogal (1997a), pp. 65-144, y (1997b), pp. 21-48.

2 Carande (1945) y (1965-67), tomo III.

${ }^{3}$ El trabajo más relevante es Sanz Ayán (1988), pp. 35-40. 
un papel relevante y que vale la pena analizarlo con detalle. Por otra parte, la figura del Factor General del rey, surgida durante el reinado de Felipe II, no alcanzó su verdadero esplendor hasta el siglo XVI, cuando junto a este importante cargo muchos otros hombres de negocios empezaron a ser nombrados no ya asentistas, sino factores.

Las funciones de los factores dentro de las provisiones de dinero no fueron nunca perfiladas con precisión. Cada uno jugó el papel que le permitió su propia capacidad y las circunstancias de una Real Hacienda en "crisis" permanente. Según Ruiz Martín, ni la Real Hacienda ni los hombres de negocios sabían qué era mejor para sus respectivos intereses, si negociar provisiones por vía de asiento o por vía de factoría, por eso alternaban continuamente los sistemas de transferencia de dinero al extranjero ${ }^{4}$. El crédito y el giro fueron tomando diferentes formas según las circunstancias y la experiencia de negociaciones sucesivas. Al evolucionar el sistema también lo fueron haciendo los propios agentes financieros que intervenían en él ${ }^{5}$.

Hasta ahora se ha dedicado poca atención a la figura del Factor General del rey. Modesto Ulloa y Ramón Carande hicieron referencia a la creación de este cargo y a algunas de sus operaciones en sus trabajos sobre la Real Hacienda ${ }^{6}$, pero apenas explicaron en qué consistían sus actividades. Sin duda el trabajo más destacado sobre este tema es el de Hernández Esteve, sobre las cuentas de Fernán López del Campo, el primer Factor General de Felipe $\mathrm{II}^{7}$. Doria expuso en un breve artículo las operaciones del último de los Factores Generales del siglo xvi, Tomaso Fieschi, pero quedaron sin abordar las específicas connotaciones de su cargo. Se trataba tan sólo de un análisis de los resultados económicos de su actividad como banquero y de sus negocios en las ferias italianas ${ }^{8}$.

Bartolomé Spinola fue el primero y más poderoso Factor General del reinado de Felipe IV, ostentando el cargo durante diecisiete años, entre 1627 y 1644 . ¿Qué significado tuvo para el entramado financiero recuperar el cargo del Factor General del rey? ¿Qué funciones se le asignaron? ¿Por qué la Corona optó por contar de nuevo con un Factor General el mismo año de la primera y más delicada bancarrota? El objetivo de estas páginas

\footnotetext{
${ }^{4}$ Ruiz Martín (1990), p. 118.

5 Gentil da Silva (1969), Felloni (1971) y (1978), Doria (1977), Braudel (1977), Trasselli (1972), pp. 983-986.

${ }^{6}$ Ulloa (1977), pp. 137, 145, 149, etc. Carande (1965-67), tomo III, pp. 317, 344 y 472 entre otras.

7 Hernández Esteve (1984), que es también un estudio de sus implicaciones contables.

${ }^{8}$ Doria (1978), pp. 279-285.
} 
es precisamente el de dar a conocer los rasgos más significativos del Factor General del rey en el siglo XVII, contribuyendo así a conocer mejor una parte del sistema financiero de los Austrias, hasta ahora apenas estudiada 9

\section{UN FACTOR GENERAL AL SERVICIO DEL REY DE ESPAÑA}

El término «factor» empezó a ser usado en el mundo mercantil para designar al gerente o encargado de la gestión de un establecimiento comercial. Su uso se generalizó en el ámbito del comercio de mercancías, pero poco a poco se fue aplicando también a la gestión e intermediación financiera. La idea de contar con un Factor General de su Majestad en el entramado organizativo de la Real Hacienda fue de Felipe II. La iniciativa nació en 1556 y estuvo enmarcada en lo que fue su gran intento por reorganizar la Hacienda castellana. Se trataba de introducir los métodos propios del ámbito mercantil privado en la gestión financiera de la Monarquía, involucrando en ello a quienes mejor dominaban estas materias: los comerciantes y hombres de negocios ${ }^{10}$.

La figura del Factor General fue ideada por la administración para centralizar la gestión de sus propios recursos, de tal manera que el trato que la Monarquía necesariamente debía mantener con los banqueros extranjeros se estableciese desde una posición más ventajosa para sus intereses. El objetivo era mejorar la gestión, y eso debía traducirse en una reducción del coste de transferencia del dinero hacia las plazas europeas, donde la Real Hacienda era deudora por sus compromisos políticos y militares. Se trataba de centralizar, unificar y ordenar la administración y conseguir así un mejor aprovechamiento de los fondos disponibles, que eran siempre escasos.

Felipe II decidió establecer un sistema de factorías para atender los negocios de su Hacienda, visto el buen resultado que un cargo con similares funciones estaba dando en Francia, Inglaterra y Portugal. La falta de una red propia de correspondientes en las principales plazas europeas le obligaba a tener que recurrir, en condiciones de inferioridad, a los hombres de negocios extranjeros, aceptando sus condiciones con independencia de

"Este trabajo adelanta parte de las conclusiones de una investigación más extensa sobre el papel desempeñado por el Factor General del rey en las finanzas reales y privadas de Castilla en el siglo xvII. Las dimensiones exigidas del texto nos han hecho prescindir de detalles, citas y análisis más extensos, en beneficio de una síntesis más esquemática.

${ }^{10}$ En esta corriente se enmarca también la incorporación de Pedro Luis de Torregrosa al servicio de la Real Hacienda de Felipe II. Hernández Esteve (1986), pp. 121 y ss. 
lo costosas que fuesen. A través de sus redes y contactos los banqueros extranjeros estaban en condiciones de suministrar fondos donde fuese preciso y en la moneda exigida. Felipe II quería disponer de un sistema similar propio que le permitiese gestionar sus fondos en el extranjero, sin estar obligado a tener que recurrir siempre a unos incómodos y exigentes intermediarios. De esta forma se constituyó un sistema de factores compuesto por personas expertas y de confianza, situadas en cada uno de los principales centros financieros de la Corona: Castilla, Flandes y Génova. El nombramiento de los Factores Generales recayó en hombres de negocios con experiencia en cuestiones financieras y, al mismo tiempo, con un reconocido prestigio entre sus iguales. Su primer Factor General en Castilla, Fernán López del Campo, era un conocido negociante burgalés establecido en Amberes.

Entre los objetivos inmediatos estaba, en primer lugar, sustituir parte de las funciones que hasta entonces cumplían los banqueros extranjeros, añadiendo mayor independencia a las finanzas reales. $Y$ en segundo lugar, mejorar las condiciones del crédito de la Real Hacienda, obteniendo más dinero y más barato. En el fondo, la principal función que se les encomendó consistió en facilitar la transferencia de fondos sirviéndose de una ágil circulación de letras de cambio amparadas por los factores de la Corona. Para que el sistema funcionase y gozase de credibilidad era necesario que cada factor atendiese con prontitud lo librado por sus compañeros. Se trataba de dar confianza al mercado, para lo cual era básico una buena y rápida corresponsalía. En caso contrario, la urgencia de un importante pago provocaría que cada Factor General tuviese que recurrir de nuevo a los hombres de negocios de la plaza donde se hallase, incurriendo en importantes gastos de intermediación. Era importante: «que todos los factores se correspondiesen y formasen un "cuerpo y masa", es decir, fuesen las partes coherentes, entrelazadas, perfectamente informadas y actuando de consuno, de un todo común» ${ }^{11}$.

Para ello se les dotó de poderes extraordinarios, como la disposición de todas las rentas libres de la Real Hacienda, y en el caso del Factor General de Castilla, incluso de los metales preciosos americanos. También recibieron autorización para obtener fondos vendiendo juros y tomar dinero a cambio, sin establecerles unos límites previos, tanto en las ferias de Castilla como en el extranjero. Se encargaron de negociar asientos, provisiones y asumieron la compra de manufacturas para la provisión de los ejércitos,

" Hernández Esteve (1984), p. 88. 
una de las funciones que hasta entonces estaban en manos de los asentistas de provisiones. La única limitación que se les impuso fue la de actuar siempre en presencia de una especie de interventor, el «contador de la Factoría General», encargado de velar por la seguridad de los fondos públicos que los factores administraban.

\section{EL FACTOR GENERAL DEL REY EN EL SIGLO XVII}

Setenta años después de su creación, y tras un período en el que nadie ocupó este cargo, el nieto de Felipe II rescató de nuevo la figura del Factor General en uno de los momentos más delicados por los que atravesó la Real Hacienda. La bancarrota de 1627 supuso una cierta ruptura con sus tradicionales aliados financieros y con una tendencia deudora insostenible. Si la Monarquía debía cumplir el papel imperial que le correspondía era imprescindible afrontar las reformas necesarias y fortalecer el sistema crediticio de cara al futuro. La presión que durante años habían ejercido los banqueros genoveses sobre las arcas reales había debilitado enormemente la capacidad crediticia de la Monarquía y estaba poniendo en entredicho su presencia en Europa.

De igual forma que Felipe II confió para la gestión en un hombre de negocios con experiencia, Felipe IV nombró a una de las personas más destacadas y solventes en los negocios financieros europeos del siglo XVII, Bartolomé Spinola ${ }^{12}$. El rey justificó su nombramiento por «la mucha noticia, inteligencia y práctica que vos Bartolomé Spinola (...), tenéis en los negocios y materias de mi Real Hacienda y de las provisiones que se hacen della dentro y fuera destos mis reinos» ${ }^{13}$.

La nueva fórmula tenía algunas limitaciones con respecto al sistema de factores establecido en el reinado anterior. Se decidió nombrar sólo a un Factor General, confiando todo el necesario sistema de corresponsalías al entramado que el propio genovés tenía en Europa como hombre de negocios privado. De esta forma el sistema de factores coordinado quedó simplificado en uno solo, con muy amplios poderes, especialmente en Castilla. Por tanto, los recursos humanos necesarios para cumplir las funciones

12 Previamente a su nombramiento, Bartolomé Spinola ya habia servido al rey con varios asientos de dinero, y en esos momentos prestaba sus servicios como Contador Mayor del Infante D. Carlos y miembro de la Junta del Donativo, lo cual significaba, como no podía ser de otro modo, que gozaba de la confianza del Conde-duque de Olivares.

${ }^{13}$ Archivo General de Simancas (AGS). Quitaciones de Corte, 9. Título de Factor General, 22-6-1627. 
que se le asignaron fue aportada por el mismo banquero. Eso no significó una brusca desaparición de los instrumentos financieros, ni de los métodos tradicionales de la Real Hacienda, que siguieron cumpliendo sus funciones habituales, como fue el caso, por ejemplo, del papel desempeñado por el embajador de España en Génova, con capacidad para negociar créditos con ciertas casas de negocios de esa República.

Como funcionarios reales que eran, los Factores Generales del siglo XvI recibían un salario a cargo de las arcas reales. Su cuantía, 3.500 ducados al año, era generosa comparada con la retribución de otros cargos públicos, equiparable a la de los principales Contadores del rey. El caso de Bartolomé Spinola fue algo diferente también en esto. En principio se estableció que su trabajo como Factor General no supusiese ninguna carga fija para las arcas reales. En aquel momento ya cobraba 600 ducados anuales como Contador Mayor del Donativo y otros 600 como Contador Mayor del Infante D. Carlos. Cuando unos años después empezó a servir también como miembro del Consejo de Hacienda siguió cobrando ambas sumas, pero ahora en razón de este nuevo cargo. Sin embargo, la retribución por sus servicios no se redujo sólo a esos 1.200 ducados. También gozó de numerosas propinas y ayudas de costa por el fiel cumplimiento de aquellas misiones que se le encargaron ${ }^{14}$. Así, por ejemplo, por gestionar de forma ejemplar el cobro de la media annata de los juros de naturales y extranjeros, Spinola recibió 6.000 ducados de ayuda de costa, además de 4.000 ducados para cada uno de los colaboradores que le habían ayudado en esa tarea. Inicialmente el rey había decidido que, en lugar de una cantidad fija se le pagase un 0,5 por 100 de lo recaudado por ese concepto, pero el Factor General insistió en que prefería los 6.000 ducados, aunque fuese menos de lo que podía corresponderle, porque necesitaba ese dinero de forma inmediata. Depender de los ritmos propios de la recaudación le podía poner entonces en un apuro ${ }^{15}$.

Las incompatibilidades que se derivaban de su cargo no son fáciles de establecer, al no constar expresamente en ningún documento de los hallados hasta ahora. Teóricamente, como persona al servicio directo del Rey, tenía prohibida su actividad privada como banquero. Su dedicación a la Corona como Factor General se establecía en términos de exclusividad, y la información privilegiada de que gozaba no podía ser nunca empleada en su propio beneficio o en el de sus amigos. Eso explica por qué liquidó

14 AGS. Quitaciones de Corte, 9. Título de Factor General, 17-4-1628.

${ }^{15}$ AGS Consejo y Juntas de Hacienda (CJH), leg. 828. Minuta, 29-6-1641. 
sus negocios en el verano de 1626, cuando cerró todas las cuentas pendientes que tenía con su hermano y renunció en su favor a todos los negocios de carácter financiero en los que estaba involucrado ${ }^{16}$. Se trataba de evitar el enriquecimiento personal de quien debía velar por los intereses del rey y disfrutar de una posición privilegiada en los mercados de dinero. De hecho, el primer Factor General, Fernán López del Campo, fue encarcelado y sus bienes embargados en 1589 , al ser acusado precisamente de lucrarse ilegalmente junto con Juan Curiel de la Torre ${ }^{17}$.

Bartolomé cuidó mucho cualquier aspecto que pudiera poner en entredicho su honra. Un ejemplo de ello fueron las gestiones que realizó a la muerte de su sobrino Gerónimo Gentil. Éste le cedió el 22 por 100 de su compañía de negocios y la tercera parte de su herencia. Antes de aceptar lo que le correspondía del testamento, Bartolomé pidió permiso al rey para que constase «que no contraviene por este acto a la obligación que tiene como criado de V. Magd. que asiste en sus reales Consejos, haviendo procurado siempre servir en todo con la puntualidad y observancia que debe» ${ }^{18}$.

El Consejo de Hacienda dio su aprobación porque, al fin y al cabo, el legado de su sobrino sólo venía a incrementar el patrimonio personal del Factor General, sin suponer ninguna interferencia en el servicio que prestaba a la Corona. Sin embargo, Bartolomé renunció a la parte de la compañía de su sobrino, que también le había sido legada, en beneficio de la compañía genovesa de su hermano Gregorio. La imposibilidad de intervenir de forma privada y con ánimo de lucro en operaciones financieras no fue obstáculo para que continuase con algunos negocios de carácter comercial, como la exportación de lana al extranjero o la aseguración. El objetivo fundamental de la incompatibilidad de su cargo con la gestión financiera de carácter privado era fundamentalmente impedir la especulación o el aprovechamiento de la información privilegiada en su propio beneficio.

A la hora de disponer de los fondos de la Real Hacienda Bartolomé Spinola tuvo mayores restricciones de las que habían tenido los Factores Generales de Felipe II. Aunque el espíritu pretendía ser el mismo, los fondos de la Real Hacienda puestos a su disposición se concretaron siempre a través de la negociación de factorías anuales, cuyo titular era el propio

${ }^{16}$ Archivio Storico dei Comune di Genova, leg. 257. Libri di conti di Gio Luca e Gregorio, 1618-1630, y leg. 263. Libri di conti di Gio Luca e Gregorio, 1626-1631.

"Hernández Estévez (1984), p. 94.

is AGS CJH, leg. 828 Consulta del Consejo de Hacienda, 12-3-1641. 
Factor General. Al igual que en los contratos de asientos, en estas factorías se establecían las sumas que el Consejo de Hacienda ponía a su disposición, así como el modo de percibirlas, siempre a cambio del crédito que él concedía a la Corona. De esta forma, aunque el Factor General se hizo cargo de la gestión de una parte muy importante de los ingresos reales, la asignación de su destino quedó siempre en manos del Consejo de Hacienda.

Los servicios prestados por el Factor General tampoco impidieron que ese Consejo siguiese negociando nuevos créditos con el resto de los hombres de negocios. Lo que demuestra que las funciones asignadas al Factor General fueron sólo complementarias y siempre estuvieron al servicio de los criterios propios de la Real Hacienda. Esa distancia entre ambas instituciones hizo innecesaria la figura del «contador de la Factoría General» creada en el reinado de Felipe II. Esta persona se había encargado de la intervención de todos los negocios del Factor General, firmando conjuntamente con él las órdenes de pago y otros documentos, así como de llevar sus libros de cuentas. La mayor autonomía de Bartolomé Spinola en cuanto a la organización de su actividad le permitió contar con sus propios colaboradores, de cuya remuneración se encargaba él personalmente, así como de establecer su propia red de correspondientes, tanto en España como en el extranjero. El encargado de fiscalizar su actuación fue en este caso la Contaduría Mayor de Cuentas, ante quien Bartolomé estuvo siempre obligado a presentar relación jurada, tal y como hacía cualquiera que hubiese recibido o administrado fondos públicos. En cierto modo Bartolomé Spinola siguió comportándose como el hombre de negocios que hasta entonces había sido, pero desde 1627 en lugar de buscar directamente su propio interés y beneficio, actuó siempre al servicio de la Real Hacienda.

\section{¿QUIÉN ERA BARTOLOMÉ SPINOLA?}

El apellido Spinola desvela con claridad su origen genovés, pero la amplitud de este linaje puede llevarnos a engaño a la hora de identificar a quienes lo ostentaban. El apellido Spinola aparece en las finanzas reales castellanas ya en el siglo xv, pero la rama familiar de Bartolomé comenzó su actividad en la Península Ibérica cuando él personalmente se trasladó e instaló en Madrid ${ }^{19}$.

${ }^{19}$ Álvarez Nogal (1997b), pp. 55-60. 
Tradicionalmente se ha considerado que la presencia en el mundo financiero castellano de unos mismos apellidos durante décadas era indicio de la continuidad de las mismas casas de negocio, tal y como ocurría en el caso de los Fugger. La realidad en el caso genovés es bien distinta. Aun tratándose de apellidos comunes que denotan un mismo linaje, muchas veces eran familias y negocios diferentes e independientes. La razón es precisamente la calidad de las actividades que traían entre manos. Era muy difícil mantener el negocio de asentista más allá de la vida de cualquiera de ellos, pues normalmente los descendientes estaban incapacitados o desinteresados para continuar a causa de la complejidad y el riesgo que suponía entablar relaciones financieras con el rey de España. Su existencia sólo se alargaba cuando un pariente cercano, involucrado de antemano en los asientos, se hacía cargo de la casa de negocios. Por esta razón, la presencia del apellido Spinola, Grimaldi o Centurión en el reinado de Felipe II no implica lazos de parentesco directo, ni continuidad en los negocios con los banqueros que después ostentaron el mismo apellido durante el reinado de Felipe IV o Carlos II. Es el caso de Bartolomé Spinola, cuya fortuna fue fruto del esfuerzo de toda una vida y de la habilidad de un hombre excepcional en el mundo de las finanzas.

Otra cosa distinta es lo que ocurría en Génova a la hora de plantearse la continuidad de ciertas casas de negocios. No podemos olvidar que muchas veces, por importantes que fuesen, los banqueros genoveses que trabajaban en la Corte de Madrid no dejaban de ser sucursales de la casa principal con sede en Italia. Su capacidad para diversificar operaciones entre las distintas plazas europeas permitía al negocio familiar en Génova una mayor estabilidad, y quizá también mayor facilidad para sobrevivir a sus fundadores.

Bartolomé nació en Génova en torno a $1587^{20}$. Sus padres, Gerónimo Spinola y Aurelia Spinola Pinelo, se contaban entre las familias más ilustres de la metrópoli italiana ${ }^{21}$. Su padre falleció cuando él contaba con poco más de veinte años y ya residía en Madrid, dedicándose de lleno al negocio

${ }^{20}$ Este dato se desprende de un documento de septiembre de 1627 en el que se le considera con cuarenta años. Archivo Histórico Nacional (AHN), Órdenes Militares, Santiago, exp. 7910. Expediente del interrogatorio para ingresar en la orden de Santiago, 1-9-1627.

${ }^{21}$ AHN, Órdenes Militares, Santiago, exp. 7910. Cédula del Consejo de Órdenes, 22-6-1627. Sus abuelos paternos son Gregorio Spinola y Pelegrina Grillo. Archivo Histórico de Protocolos Notariales de Madrid (AHPNM), protocolo 5787, fol. 322. Fenecimiento de cuenta y liberación, 16-6-1626. 
mercantil ${ }^{22}$. Tenía tres hermanos: Gregorio, María Eugenia y Pelegrina. Maria Eugenia ingresó como religiosa en el convento de San Sebastián, en la misma ciudad de Génova. Pelegrina se casó con Giulio Gentile, un hombre de negocios genovés, uno de cuyos hijos, Géronimo, se instaló también en Madrid y negoció asientos con la Corona, asesorado por su tío Bartolomé. Gregorio, al ser el hermano mayor, siguiendo la costumbre de la época, se quedó en Génova bajo la tutela de su padre, y después de su muerte se hizo cargo de la administración del patrimonio familiar. En 1610 fundó con otro socio una compañía de negocios titulada «Juan Lucas y Gregorio Spinola». La presencia de su hermano en Madrid facilitó que ambos pudiesen entrar poco después en el negocio financiero internacional: el de mayores riesgos, pero también el más lucrativo. Bartolomé se casó en España con doña María de Benavides, sin embargo no tuvo descendencia ${ }^{23}$. Quizá por ese motivo protegió y ayudó siempre que pudo a su sobrino Gerónimo Gentil, a quien consideró su propio hijo. Desgraciadamente su protegido falleció pocos años antes que él.

Como consecuencia de los importantes servicios que fue prestando al rey de España, Spinola fue adquiriendo un reconocimiento social ${ }^{24}$ que le permitió fortalecer su nombre en los negocios, donde la reputación era una de las piezas claves del éxito. Poco después de ser nombrado Factor General se le concedió un hábito en la orden de Santiago ${ }^{25}$ y fue nombrado Comendador de la Oliva. Ingresó en los Consejos de Hacienda y de Guerra, interviniendo en la toma de decisiones políticas y económicas del reinado de Felipe IV. También se convirtió en el Tesorero General de la Media annata. Junto a títulos y nombramientos fue consolidando su patrimonio personal. Así, en agosto de 1626 compró Espinar ${ }^{26}$, apartando a esta población de la jurisdicción de la ciudad de Segovia y convirtiéndola en villa. Ya al final de su vida, en 1642, se le concedió el título de conde de Pezuela de las Torres ${ }^{27}$.

22 AHPNM, protocolo 4305, fol. 393. Poder, 4-3-1614.

${ }^{23}$ AHPNM, protocolo 4530, fol. 248. Liquidación, 9-6-1644.

${ }^{24}$ Elliott (1991), p. 308.

${ }^{25}$ AHN, Órdenes Militares, Santiago, exp. 7910. Cédula del Consejo de Órdenes, 22-6-1627.

${ }^{26}$ AHPNM, protocolo 4530, fol. 206. Liquidación, 12-5-1644. Se obligó a pagar 15.000 mrs. por cada vecino del lugar y 5.600 ducados por legua legal, entregando el total en reales de plata doble, más un interés anual del 8 por 100 . La averiguación que se hizo de la población dio como resultado 372 vecinos, mientras que el medidor declaró tener 139.740.564 varas cuadradas.

${ }^{27}$ Archivo General de Indias (AGI), Contratación, leg. 4693-2. Libro de cargo y data. 
Bartolomé Spinola murió el 13 de febrero de $1644^{28}$. Su principal heredero fue la compañía genovesa que su hermano Gregorio había fundado en Génova con su socio Juan Lucas Spinola. Precisamente fue Jacome María Spinola, el hijo de Juan Lucas, quien se hizo cargo de la casa de negocios de Bartolomé y se convirtió en el Tesorero General de la Media annata. Unos años después, tras la muerte de Paolo, el hijo de Gregorio, ese amigo de la familia asumió también el título nobiliario de Bartolomé, pasando a ser el III Conde de Pezuela de las Torres. Su importancia en las finanzas de la Monarquía fue mucho menor que la del Factor General. Después de un tiempo liquidando cuentas y atendiendo acreedores, en 1650 estuvo ya en condiciones de hacerse cargo de un asiento para la provisión de dinero en el extranjero, pero su actividad principal se desenvolvió fundamentalmente en el préstamo a la Tesorería General de Madrid.

\section{LOS PRIMEROS AÑOS DE BARTOLOMÉ AL FRENTE DEL NEGOCIO PRIVADO}

Su vocación comercial y los conocimientos que adquirió sobre los mecanismos del mercado, especialmente el financiero, se explican perfectamente por su contexto familiar. A su padre se le consideraba en Génova un hombre de negocios, pues acostumbraba a prestar dinero como otros muchos nobles genoveses $^{29}$. La primera noticia que tenemos de Bartolomé en Madrid es la fundación de una compañía de negocios con Juan Andrea Spinola, con quien no guarda ninguna relación de parentesco a pesar de tener ambos el mismo apellido.

La compañía titulada «Juan Andrea y Bartolomé Spinola» se constituyó como tal el 5 de marzo de 1611 , con una duración máxima de tres años ${ }^{30}$. Los buenos resultados obtenidos en ese tiempo les permitieron prorrogarla otros tres más en $1614^{31}$, y así sucesivamente. Al tratarse de personas reconocidas entre sus compatriotas, recibieron pronto el encargo de ges-

28 AGS CJH, leg. 872. Consulta, 15-2-1644. Pellicer (1965), Aviso, 16-2-1644, citado por Domínguez Ortiz (1960), p. 105, nota 6. «Murió ayer el señor Bartolomé Spinola, (...) herédale un sobrino que está en Génova.» Ese sobrino era Paolo Spinola, el hijo de Gregorio, pero sólo heredó su título. Los negocios de su casa en Madrid pasaron, como hemos dicho, a Jacome María, el hijo del socio de Gregorio.

${ }^{29} \mathrm{AHN}$, Ordenes Militares, Santiago, exp. 7910. Expediente del interrogatorio para ingresar en la orden de Santiago, 1-9.1627.

30 AHPNM, protocolo 4305, fol. 393. Poder, 4-3-1614.

${ }^{31}$ AHPNM, protocolo 4305, fol. 393. Poder, 4-3-1614. 
tionar las rentas y pequeñas inversiones que algunos genoveses tenían en la Península Ibérica, cobrando por ello una pequeña comisión. Así, en 1615 se hicieron cargo del cobro de un juro situado en Granada cuyo titular era Oracio Doria. Ese mismo año Angelo Lomelin, genovés residente en Madrid, les dio un poder de carácter general para negociar y cobrar deudas en su nombre ${ }^{32}$. En ocasiones la compañía de Bartolomé se hizo cargo de ese tipo de operaciones adelantando el dinero a los acreedores. En 1625 Juan Pedro y Juan Francisco Bozo cedieron a Spinola la cantidad que les adeudaba un mercader de Madrid ${ }^{33}$. También actuaron como intermediarios entre los particulares y el Depositario General de la Corte, descontando libranzas sobre él, pues con frecuencia el salario del personal de los Consejos y Secretarías de la Corte era librado sobre dicho Depositario a pesar de ser conocida la demora de sus pagos ${ }^{34}$.

A medida que el negocio fue consolidándose, también aumentó la diversificación en su estrategia inversora, atreviéndose incluso a aportar capital en la constitución de algunos negocios de carácter comercial que frecuentemente surgían en la Corte. Francisco Forneli y Domingo Lamberti constituyeron un negocio de ultramarinos especializado en la venta de conservas y confituras, abriendo su establecimiento en la Carrera de San Gerónimo. Mientras Lamberti, como confitero, se encargaba de la gestión de las tiendas, Forneli, el socio capitalista, asumió el papel comercial y se hizo cargo del suministro de la materia prima. El 65 por 100 del capital necesario para ponerlo en marcha fue aportado por la compañía «Juan Andrea y Bartolomé Spinola» ${ }^{35}$. Pero ellos no participaron como socios en su constitución, simplemente prestaron a sus titulares la parte más importante del capital que la hizo realidad.

Éste no fue el único ámbito comercial en el que intervinieron. Uno de los negocios donde más involucrado estuvo Bartolomé Spinola fue el comercio y exportación de lana. Al igual que hizo el resto de los financieros genoveses, Spinola se encargó de comprar materia prima y enviarla a Italia. En 1628 y 1629, siendo ya Factor General, encargó a su agente de lanas, Lazaro Midense, vecino de Madrid, que recogiese la que había comprado en Segovia y la embarcase en el puerto de Alicante ${ }^{36}$. En 1628 Spinola

32 AHPNM, protocolo 4503; fol. 225. Poder, 15-8-1615.

${ }^{33}$ AHPNM, protocolo 4511. Poder, 2-1-1625.

34 AHPNM, protocolo 4511. Escritura, 4-4-1625.

is AHPNM, protocolo 4505, fol. 214. Escritura, 9-4-1618.

36 AHPNM, protocolo 4513, fol. 756. Poder 9-12-1628. Midense también era correspondiente de lanas de Octavio María Cavana y de otros hombres de negocios genoveses. 
había intentado hacerse con toda la producción del monasterio de El Escorial. Sin embargo, la justicia le impidió la compra en exclusiva y tuvo que compartir la mitad de esa lana con Francisco de Riofrío, Tomás de Vergara, doña María Dávila y Francisco de Cabañas, todos ellos fabricantes de paños en la ciudad de Segovia. De nada le sirvió apelar a la Real Chancillería de Valladolid, ni el haber pagado por adelantado y en plata doble cuando el resto lo hizo en vellón ${ }^{37}$. Otra actividad en la que encontramos a Bartolomé Spinola fue la contratación de seguros, un lucrativo negocio al que también se había dedicado inicialmente Gregorio en Génova ${ }^{38}$. Tenemos noticia de la actividad asegurativa de Bartolomé por un infortunio sucedido en 1627 , al tener que hacerse cargo del pago al contado y en plata doble del siniestro de un navío ${ }^{39}$.

Estas intervenciones en los mercados de lana o de seguros, incluso después de ser nombrado Factor General, son algunos ejemplos de la diversificación de actividades de un hombre de negocios. El objetivo de Bartolomé y de su socio fue consolidarse cuanto antes en el ámbito mercantil para poder intervenir después en la negociación crediticia con particulares y especialmente con la Corona. El objetivo era, como no podía ser de otra forma, controlar la mayor parte posible de metales preciosos e intervenir con ellos en las ferias de pagos. Esa preferencia por el negocio financiero en detrimento del comercio se fue concretando en una mayor concesión de créditos a particulares hasta convertirse en la principal actividad de su compañía.

Uno de los ramos más importantes de su incipiente actividad financiera fue la gestión de fondos privados. Por una parte, la compañía aceptaba depósitos de particulares, a los que pagaba un interés por el tiempo que les confiasen su dinero hasta un 7 por 100 anual en el mejor de los casos. Con esos depósitos la compañía dispuso de liquidez para negociar en las ferias de pagos, donde los beneficios podían llegar fácilmente al 15 por 100 o incluso ser superiores si se conocía bien el mercado ${ }^{40}$.

Poco a poco la importancia de sus operaciones fue creciendo, ampliando su ámbito de actuación y no limitándose sólo a la mera administrảción

${ }^{37}$ AHPNM, protocolo 4513, fol. 128. Poder, 18-2-1628.

38 Álvarez Nogal (en prensa).

34 AHPNM, protocolo 4513, fol. 752. Carta de pago, 4-12-1628. Luis Enriquez Cardoso había asegurado con Bartolomé dos cajas de azúcar valoradas en 750 reales de plata doble en la nave «Nuestra Señora del Rosario», que debía haber llegado a Lisboa desde Río de Janeiro. La nave fue capturada y asaltada por piratas que la llevaron a Holanda, perdiéndose la carga.

*1 Ghilino (1996), p. 121; Doria (1978), p. 291. 
de patrimonios. Así, en 1618 se hicieron cargo de cobrar el alcance del Medio General que aún estaba pendiente, firmado por la Real Hacienda con los hombres de negocios el 14 de febrero de 1598. Se trataba de 8.000 ducados que la compañía adelantó al que por entonces era su beneficiario, Juan Pío Marín. Ellos asumieron el encargo de cobrar más tarde ese dinero de la Real Hacienda ${ }^{41}$. La consolidación de su nombre en un mercado tan peligroso les hizo ganar clientes, y eso les permitió aumentar el volumen y la complejidad de sus operaciones hasta que por fin estuvieron en condiciones de negociar con el rey de España. La entrada en los asientos de la Monarquía era uno de los aspectos más rentables y apetecidos por los hombres de negocios genoveses: la puerta que les daba paso a la manipulación de grandes cantidades de metales preciosos y a que su nombre adquiriese un gran prestigio.

\section{LA CONEXIÓN DE BARTOLOMÉ SPINOLA CON OTRAS COMPAÑÍAS DE NEGOCIOS}

La necesidad de establecer el mayor número de contactos y extender las redes de influencia para poder estar presentes en las principales plazas europeas llevó a Bartolomé Spinola y a su socio a buscar aliados entre las casas de negocios que tenían sede en Génova, Amberes, Milán, Sevilla y el resto de las principales plazas europeas. Había varios cauces para establecer una cooperación entre dos o más compañías. Las formas más comunes consistían en conceder una participación en la propia compañía a cambio de un aporte de capital, en buscar socios exclusivamente para una determinada operación o bien tener abierta una cuenta corriente de forma permanente en la otra compañía. En el primer caso era necesaria una gran confianza entre los socios, y normalmente se daba cuando había lazos de parentesco. A través de esta fórmula de colaboración además de contar con un fiel aliado en otra plaza se establecía un reparto de los beneficios de cualquiera de las operaciones llevadas a cabo, pues la compañía aliada era copropietaria del negocio. En el segundo y tercer caso, más comunes, la relación era menos estrecha y comprometida. Se solían ceder parte de los beneficios de una operación concreta cuando las dimensiones de la operación o el riesgo eran muy elevados, de igual modo que se hacía con los seguros. Con la fórmula de la apertura de una cuenta las compañías

${ }^{41}$ AHPNM, protocolo 4505, fol. 43. Poder, 24-1-1618. 
se limitaban a realizar las operaciones que fuesen ordenadas por sus titulares. El cuentacorrentista estaba autorizado a disponer de una cantidad por encima de sus fondos efectivos, concediéndole crédito durante un tiempo establecido de común acuerdo.

La compañía madrileña «Juan Andrea y Bartolomé Spinola» tenía una relación especial y permanente con la compañía genovesa «Juan Lucas y Gregorio Spinola», que se explica por su parentesco ${ }^{42}$. Ellos fueron sus principales colaboradores y aliados en Italia, especialmente en las ferias de Nove y Plasencia. Ambas compañías se cedieron un 25 por $100 \mathrm{del}$ beneficio de sus respectivos negocios. A su vez, las dos establecieron diferentes vínculos con otras casas. Por ejemplo, la compañía de Bartolomé Spinola cedió parte de los primeros asientos que negoció con la Real Hacienda a la compañía «Esteban Palavesín y Franco Spinola».

A comienzos de la década de los años veinte, al morir en 1620 su socio Juan Andrea, Bartolomé amplió su red de colaboración en Génova con «Franco Spinola y David Imperial» y «Julio y Jorge Sanguinetos», a los que cedió participaciones en cuatro asientos que, por valor de 1.258 .000 escudos y ducados, concertó entre 1621 y 1622. Esa cooperación se concretó después con el envío de dinero en efectivo desde Madrid ${ }^{43}$. En Amberes, su más directo colaborador fue la compañía «Paulo Bustanzo y hermanos», y en caso de dificultades también contó con la colaboración de «Lázaro Benito y Andrea Piquinoti». En Venecia su contacto era «Felipe David Imperial y Francisco M. Spinola». En París y Lyón, «Juan Andrea, Bartolome Lumaga y Pablo de Pablo Mascranico». En Lisboa, la compañía de Juan de Argomedo y «Juan María Chape y Manuel Corbru». Por último, en Sevilla estableció relaciones con dos importantes compañías: «Antonioto Spinola y Alexandro Grimaldo» y «Juan Esteban de la Torre y Francisco M. Piquinotti» ${ }^{44}$. El permitir la entrada de otros suponía, por una parte, repartir el riesgo de las provisiones, pues en muchas ocasiones una sola compañía no tenía recursos suficientes para hacer frente a los anticipos de dinero que exigían los asientos. Por otra, se contaba con un número mayor de aliados en el extranjero, que en el fondo agilizaba las transferencias y en el futuro podía permitir una mayor capacidad de negociación de nuevos créditos.

\footnotetext{
42 AHPNM, protocolo 5787, fol. 310. Escritura, 16-6-1626.

${ }_{43}$ AHPNM, protocolo 4511. Poder, 8-1-1625.

t4 AHPNM, protocolo 4510, fol. 52. Poder 16-1-1624.
} 


\section{LOS SERVICIOS PRESTADOS A LA CORONA COMO BANQUERO PRIVADO}

El primero de los asientos del que tenemos constancia que la Corona negoció con la compañía «Juan Andrea y Bartolomé Spinola» se firmó el 10 de octubre de 1615 y consistió en la provisión de 40.000 ducados plata en la Tesorería General de Madrid. El dinero debía servir para cancelar algunas deudas que la Real Hacienda aún tenía pendientes con sus acreedores del Medio General de $1608^{45}$. Además de las consignaciones pertinentes en cualquier asiento, la compañía de genoveses disfrutó de juros de resguardo, situados en este caso sobre la renta del medio por ciento de Sevilla ${ }^{46}$. La puntualidad con la que cumplieron en este primer crédito les abrió las puertas a nuevos asientos. Ese mismo año se les concedió una licencia de saca para enviar dinero a Italia, lo cual demuestra que seguramente además del asiento de octubre también se hicieron cargo de una provisión más en el extranjero. Gaspar de Grasa llevó en su nombre 300.000 reales de plata a Cartagena para embarcarlos allí en las galeras en dirección a Génova ${ }^{47}$. El segundo asiento del que tenemos constancia se firmó en febrero de 1617 por un valor de $611.666,6$ escudos y ducados, de los cuales 218.333,3 escudos eran para Flandes y $91.666,6$ escudos para Milán.

En 1620 Bartolomé Spinola formaba parte del consorcio de genoveses que firmaron una provisión de 1.500 .000 ducados para Flandes, Milán y Génova. Entre los partícipes encontramos a Esteban Spinola, Vicencio Squarzafigo, Agustín Justiniano, Francisco Serra y los hermanos Juan María y Octavio María Cavana. La contribución de Spinola era de 250.000 ducados. La consignación más importante de este asiento fue el dinero secuestrado a los particulares en las flotas que ese año habían llegado de América. En total 800.000 ducados que se entregaron a los banqueros en la Casa de la Contratación ${ }^{48}$.

Además del suministro de fondos, entre los servicios que prestó a la Corona se encuentra la financiación de dos galeras en la escuadra de Génova. Cuando falleció Jacome Marín el rey solicitó a Bartolomé y a su hermano que se hiciesen cargo de mantener las dos galeras que aquél dejaba desa-

45 AHPNM, protocolo 5787, fol. 479. Renuncia, 22-11-1626.

th AHPNM, protocolo 4503, fol. 271. Poder, 4-11-1615.

${ }^{47}$ AHPNM, protocolo 4503, fol. 335. Carta de pago, 24-2-1616.

"\$ AGS CJH, leg. 624-1-13. Cédula 29-3-1621. 
tendidas ${ }^{49}$. Este servicio se mantuvo hasta la muerte de Bartolomé y le sucedió su sobrino Paolo Spinola. Otra muestra de la confianza que ya tenía en él la administración real fue su nombramiento en diciembre de 1626 como Depositario general de los bienes embargados a los súbditos franceses que entonces trabajaban en España ${ }^{50}$.

\section{EL NOMBRAMIENTO COMO FACTOR GENERAL DEL REY Y SUS FUNCIONES}

Durante la década de los años veinte la coyuntura económica permitió que los banqueros genoveses actuasen en bloque frente a la Real Hacienda. Esa posición de fuerza en la negociación del crédito obligó a la Real Hacienda a buscar competidores y alternativas. La solución llegó actuando en tres frentes. En primer lugar se decretó la primera bancarrota del reinado con el objeto de renegociar la deuda, desbloqueando así unos recursos que ya estaban hipotecados en el futuro. En segundo lugar, se dio entrada a los hombres de negocios portugueses en la negociación del crédito, pues al aumentar el número de banqueros y la competencia entre ellos bajaría el precio y las exigencias de quienes se consideraban imprescindibles. La tercera medida, destinada a racionalizar y hacer más eficaz el funcionamiento del sistema financiero consistió en resucitar la olvidada figura del Factor General del rey. Todas estas medidas fueron discutidas y tomadas en el invierno de 1626-1627. Por esta razón, el nombramiento de Spinola al frente de las finanzas de la Corona no fue una acción aislada, sino que se trató de un hecho premeditado, con una clara intención de fortalecer y ampliar el crédito de la Monarquía.

Desde el verano de 1626 da la impresión de que Bartolomé Spinola ya sabía que se le iba a nombrar Factor General y las consecuencias que se derivaban de ese cargo, pues fue entonces cuando comenzó a zanjar todas las cuentas y negocios que mantenía con su hermano. De hecho,

19 AHPNM, protocolo 5787, fol. 305. Fenecimiento de cuenta, 13-6-1626. Ricardo Petrocholi se encargó de la administración y gestión de los fondos destinados a esas embarcaciones. AGS CJH, leg. 1051. Minuta de Juan Domingo Spinola, 13-6-1656.

50 Esta incautación de bienes de extranjeros era una represalia por el secuestro de una galera cargada con dinero que se dirigía de Barcelona a Génova. La detención de la embarcación fue llevada a cabo por el duque de Guisa, con el consentimiento del rey de Francia. Los fondos incautados a los franceses debían servir para compensar las pérdidas de los hombres de negocios cuyo dinero iba en el barco interceptado. AHPNM, protocolo 5787, fol. 498. Poder, 6-12-1626. 
Gregorio se desplazó a España y trabajó durante unos meses en Madrid junto a él. Resulta muy extraño que después de años de esfuerzo por ganarse la confianza del mercado, Spinola cerrase la mayor parte de sus negocios precisamente cuando los saldos de todas esas operaciones eran muy positivos.

Quizá uno de los cometidos más importantes del Factor General fue su papel como asesor financiero. Con frecuencia Bartolomé Spinola asesoró sobre la negociación de créditos y sobre lo que convenía hacer cuando se trataba de la moneda. Por su experiencia como asentista sabía perfectamente si los hombres de negocios exageraban o no a la hora de negarse a entrar en la negociación de nuevos créditos. Valoraba la calidad de las consignaciones y aconsejaba hasta dónde se les podía apretar para doblegarles a aceptar las pretensiones de la Real Hacienda.

Por ejemplo, en diciembre de 1633 se estaba negociando con Carlo Strata un asiento de 1.046 .000 escudos. Se le iba a pagar parte de sus consignaciones con dinero disponible en Cerdeña, pero Strata exigió que se le asegurara el cobro de esa consignación entregándole letras aceptadas en Génova por personas solventes, aunque ello implicase un retraso de tres meses en los pagos. Bartolomé Spinola se opuso frontalmente a que el Consejo admitiese la exigencia del banquero genovés. Si se le concedían las letras además de las consignaciones en Cerdeña, recibía un doble beneficio, porque cobrar en Génova las letras era, «sin comparación», mejor consignación que si se le pagaba al contado en Madrid, pues «no pierde día alguno de dilación para extinguir los intereses» 51 .

Al fin y al cabo, todos los hombres de negocios acababan remitiendo dinero a Génova, donde estaban parte de sus descubiertos. Si se aseguraba a Strata el pago allí con letras aceptadas, se le evitaba la incertidumbre del envío del dinero y su posible retraso. En fin, demasiadas seguridades para alguien al que, con seguridad, se le acabaría pagando bien por la importancia que tenía esa operación. Además había que tener en cuenta que el resto de consignaciones de este asiento se podían cobrar anticipadamente, incluso se le daba la posibilidad de consumir los juros o venderlos para obtener liquidez cuanto antes. En total no venían a quedar más de 50.000 ducados de consignación sin estar respaldados en el momento de efectuar los pagos en un asiento de más de un millón de escudos. Según Bartolomé Spinola, al fijar las consignaciones «se deve ponderar la calidad y no la cantidad, y ser la cantidad en beneficio de quien toma el asiento» 52 .

\footnotetext{
51 AGS CJH, leg. 714. Consulta del Consejo de Hacienda, 20-12-1633.

52 AGS CJH, leg. 714. Consulta del Consejo de Hacienda, 20-12-1633.
} 
Análisis como éste son abundantes entre la documentación del Consejo, órgano para quien la opinión del Factor General se convirtió en esencial a la hora de negociar con los hombres de negocios. Muy significativos y esclarecedores son sus puntos de vista sobre la participación de los portugueses en las finanzas de la Monarquía. En este sentido son sumamente representativas la valoración y explicaciones de Spinola sobre la conveniencia de negociar provisiones por «vía de asiento» o por «vía de factoría», así como el beneficio que obtenían los hombres de negocios.

No siempre su visión fue en contra de los banqueros extranjeros; al fin y al cabo él comprendía mejor que ninguno la mutua necesidad que existía entre financieros y finanzas públicas y lo importante que era conservar su crédito. En varias ocasiones salió en su defensa, sin importarle las críticas que por ello pudiera recibir o las suspicacias que sus enemigos pudieran filtrar en su contra. Desenvolverse con soltura en la Corte suponía estar dispuesto a luchar contra los «dimes y diretes» y las acusaciones anónimas, que abundaban tanto como las adulaciones y halagos. En junio de 1634 el Factor General no cesó de criticar con dureza los embargos que la Inquisición estaba practicando en Flandes. En su opinión, estas intervenciones no hacían más que perturbar y crear confusión en los mercados, perjudicando innecesariamente el crédito de los hombre de negocios ${ }^{53}$.

\section{OPERACIONES AL SERVICIO DE LA REAL HACIENDA}

Una de las operaciones más importantes de las que se encargaba el Factor General fue la de suplir cualquier urgencia a la hora de efectuar pagos en el extranjero, tanto en la disposición inmediata de dinero como en la búsqueda de los cauces más adecuados y baratos para la Real Hacienda. En marzo de 1634 se necesitaba dinero urgentemente en Alsacia. La demanda procedía del Cardenal Infante y del duque de Feria. Ese mes había fallecido Wallenstein y el ejército reunido en Milán estaba a punto de partir hacia Flandes. Unos meses después se conseguiría la importante victoria de Nordlingen sobre el ejército sueco. A esas alturas del año era difícil encontrar un aporte extraordinario de dinero, pues entre otras cosas no había en las arcas reales con qué negociarlo. Se decidió entonces pedirle a Carlo Strata que desviase 255.000 escudos hacia Alsacia, descontándolos de lo que debía proveer en Flandes. La respuesta del banquero genovés

${ }^{53}$ AGS CJH, leg. 714. Consulta, 21-6-1634. 
fue bastante impertinente, y exigió una revisión del precio de sus provisiones. En primer lugar, la escolta con el dinero que debía ir de contado hasta Alsacia debía correr por cuenta de la Real Hacienda; por otro, el precio de cada escudo aumentaba en 15,3 maravedíes. Si por cada escudo que situase en Flandes, Strata pedía 352,6 maravedíes, en Alsacia no lo haría por menos de 368 maravedies. Ante tanta exigencia, la Real Hacienda recurrió al Factor General, que se encargó de esta provisión utilizando los fondos negociados en la factoría de ese año. En este caso, el cambio de destino no implicó mayores costes porque Spinola aceptó realizar el servicio «sin costa ni daño alguno de la Real Hacienda» ${ }^{54}$.

Uno de los encargos más complicados que recibió Bartolomé Spinola de la Administración real fue el cobro de las contribuciones concedidas por las Cortes de Aragón y Valencia. La cuantía de esos fondos se puso a disposición de la negociación de asientos, convirtiéndose así en consignaciones dispuestas a ser asignadas como pago de un crédito. Sin embargo, el cobro de esas sumas estuvo siempre lleno de dificultades. Estos territorios pusieron todas las trabas posibles para impedir que la administración castellana recaudase ese dinero con facilidad, quizá para hacerla desistir a la hora de solicitar más ayudas en el futuro. Ahora bien, la dificultad en el cobro era una de las causas que más dañaba la imagen de una consignación y, por tanto, el que fuese aceptada por los banqueros en la negociación de un crédito. Algunos genoveses y portugueses habían recibido inicialmente este tipo de libranzas, pero pronto empezaron a llegar quejas al Consejo ante la imposibilidad de hacerlas efectivas. La Real Hacienda no tuvo más remedio que reconocer las dificultades que entrañaba cobrar en Valencia y Aragón y la imposibilidad de utilizar ese dinero para negociar créditos con él. El desplante que recibieron los banqueros suponía un lastre para el futuro. Como las consignaciones habían salido inciertas, nadie volvió a adelantar dinero teniendo como garantía del reembolso este tipo de fondos, incluso aunque las Cortes de aquellos reinos aceptasen conceder nuevos servicios. Bartolomé Spinola recibió la orden de gestionar el cobro de ese dinero, así como de percibir también el donativo gracioso que por entonces se había solicitado en Aragón. Sólo el Factor General estaba en condiciones de superar las dificultades y recaudar el dinero que teóricamente debían rendir esas contribuciones. La función de intermediario del Factor General sirvió para poner de nuevo al servicio de la negociación de nuevos créditos esos fondos difíciles de cobrar.

${ }^{54}$ AGS CJH, leg. 714. Consulta, 11-3-1634. 
Otra actividad con un objetivo muy similar fue gestionar la venta de vasallos y oficios (cuadro 1). Desde su incorporación al servicio de la Corona quedaron a su cargo las enajenaciones más importantes del patrimonio real. El fruto de esas ventas estaba destinado a cubrir los adelantos que Bartolomé Spinola hacía en sus factorías. Se trataba, por tanto, de consignaciones con características especiales, pues ni tenían ajustada una cantidad fija (el importe exacto sólo se sabría después de realizar las ventas, lo demás eran especulaciones) ni una fecha límite para ser cobradas. Precisamente dos de los rasgos más importantes que debía tener una consignación. Un banquero jamás se atrevía a comprometer su dinero con la Corona sin saber exactamente el importe de la contrapartida y la fecha de su cobro. Sin embargo, la condición de Factor General y las características propias de una provisión por «vía de factoría» hicieron posible que Spinola aceptase este tipo de pago de la Real Hacienda a pesar de su riesgo. Y por otra parte, permitió a la Corona disponer de crédito sin tener inicialmente con que respaldarlo.

Entre las enajenaciones de que se encargó Spinola encontramos tanto la venta de vasallos y jurisdicciones, como la de distintos oficios: regidor, alguacil, escribano, tesorero, etc. El mismo año que fue nombrado Factor General se negoció con él una venta de vasallos con la que se resarcirían sus anticipos en Flandes y Madrid. De hecho, los dos asuntos que podían hacer prosperar las provisiones de dinero ese difícil año de 1627 eran, en primer lugar, llegar a un acuerdo en el Medio General con los banqueros afectados por la bancarrota, y en segundo, pero no menos importante, la venta de vasallos. Según el Consejo de Hacienda, «paradas estas dos cosas, corre el tiempo», y se temía que por no tener medios para pagar los plazos de los créditos fallasen las provisiones que se habían concertado con los hombres de negocios 55 .

Unos años después, el 15 de mayo de 1630 , se puso en marcha la primera gran enajenación de oficios del siglo xvil. Se trataba de vender una regiduría por concejo y una vara de alguacil mayor, así como de reducir el número de escribanos reales. El Factor General también se hizo cargo de estas enajenaciones como satisfacción por lo adelantado en Flandes y Alemania ${ }^{56}$. De los pormenores de la venta debía informar regularmente

"Además estaba pendiente con él un asiento de 94.000 ducados para la provisión de la Armada, cuya consignación también era lo obtenido con estas ventas. AGS CJH, leg. 632. Consulta, 27-7-1627.

s6 AGS CJH, leg. 665-2-1. Consulta del Consejo de Hacienda, 14-3-1630. 
al Consejo, pero se le concedieron grandes facultades, entre ellas incluso el poder votar en él cuando se tratase de esta materia.

\section{CUADRO 1}

Ventas de oficios y vasallos gestionadas por el Factor General del rey como consignación de sus provisiones en el extranjero

\begin{tabular}{cccc}
\hline Cédula & Ventas & Escudos $^{56}$ & Lugar de provisión \\
\hline $22 / 09 / 1629^{57}$ & $\begin{array}{c}\text { Resto de la venta de } \\
20.000 \text { vasallos, alca- } \\
\text { balas, tercias y otros } \\
\text { efectos de } 1625\end{array}$ & & \\
\hline & 20.000 vasallos & 1.290 .000 & España, Flandes y Alemania \\
\hline $15 / 05 / 1630$ & $\begin{array}{c}12.000 \text { vasallos, regidor } \\
\text { perpetuo, reducción } \\
\text { de escribanias reales }\end{array}$ & 666.000 & Flandes y Alemania \\
\hline $08 / 06 / 1630$ & $\begin{array}{c}\text { Alguaciles mayor y regi- } \\
\text { dores perpetuos }\end{array}$ & 666.000 & Flandes y Alemania \\
\hline $30 / 01 / 1633$ & $\begin{array}{c}\text { Escribanias y tesorerías } \\
\text { de Millones }\end{array}$ & 600.000 & Flandes y Alemania \\
\hline $11 / 03 / 163958$ & $\begin{array}{c}\text { 8.000 vasallos y Conta- } \\
\text { durías de Millones }\end{array}$ & 600.000 & Factoría \\
\hline
\end{tabular}

FUENTE: AGS Consejo y Juntas de Hacienda.

A veces, para cumplir con las obligaciones que le imponía el desempeño de su cargo, el Factor General comprometió su propio patrimonio. Así, en septiembre de 1629 Spinola envió dinero de contado a Italia ante las dificultades que tenía para encontrarlo a crédito en las ferias italianas a causa de la escasez de letras de cambio libradas sobre esos mercados. Consiguió reunir el dinero en efectivo vendiendo algunos de sus juros. Se trataba de tener liquidez de inmediato, y para ello no tuvo más remedio que malvender lo mejor de sus rentas ${ }^{59}$.

\footnotetext{
57 El escudo equivale en unidad de cuenta a 340 maravedíes.

58 AGS CJH, leg. 654. Consulta del Consejo de Hacienda, 20-5-1628.

59 Ripia (1768), p. 356.

(x) AGS CJH, leg. 656. Consulta, 4-9-1629.
} 


\section{LA INTERVENCIÓN DEL FACTOR GENERAL EN LA GESTIÓN DEL VELLÓN}

Ya hemos señalado cómo la Real Hacienda se apoyó en el Factor General con objeto de negociar en mejores condiciones el crédito que anualmente necesitaba tanto dentro como fuera de Castilla y fortalecer así sus transferencias de numerario al extranjero. Es lógico que entre las funciones que asumió Spinola estuviese la de intervenir en la manipulación de la moneda de vellón en favor de la arcas reales, pues el cobre se había convertido en un elemento clave en la negociación crediticia del siglo XVII. Incluso ya antes de ser nombrado Factor General se le había pedido consejo para solucionar los problemas que en 1626 estaba causando la moneda de cobre ${ }^{60}$.

Spinola gestionó una parte de los trueques de vellón a plata a los que obligatoriamente debía comprometerse la Real Hacienda con los hombres de negocios cuando se firmaban los asientos. Los fondos que manejaba el Factor para efectuar los cambios de moneda eran de la propia Real Hacienda, pero su intervención era esencial para los intereses de la Corona por su gran experiencia en el mercado de dinero y su probada lealtad.

A finales de 1627, poco después de su nombramiento como Factor General, Bartolomé Spinola recibió la orden de hacerse cargo de todos los cambios de vellón a plata en el que estuviese interesada la Real Hacienda, cualquiera que fuese la caja o los fondos afectados. De hecho, el Consejo de Cruzada quiso encargar esto a su Tesorero General, por entonces Julio César Scazuola, pero el Consejo de Hacienda se opuso terminantemente alegando que era preferible que en esta materia todo corriese «por una sola mano» ${ }^{61}$. En el fondo, lo que se pretendía era impedir que la competencia entre los propios agentes de la Real Hacienda a la hora de demandar metales preciosos provocase que el coste del cambio siguiese subiendo.

La escrupulosidad con la que Spinola sirvió a la Corona en estas operaciones fue intachable, al igual que su extensa actividad como Factor General. Esa actitud le acarreó en numerosas ocasiones la enemistad o el enfrentamiento con algunos banqueros. En una ocasión Esaú del Borgo elevó sus quejas al Consejo de Hacienda por la estrechez con que le trataba el Factor General. Spinola debía pagarle con vellón una suma de plata de la que Esaú era acreedor, pero sólo aceptaba un premio del 24-26

${ }^{6}$ Elliott (1991), p. 275.

${ }_{62}$ AGS CJH, leg. 632. Consulta del Consejo de Hacienda, 21-11-1627. 
por 100 cuando según el banquero florentino el cambio real en la calle corría entre el 25 y el 28 por $100^{62}$. Lo cierto es que a finales de junio de ese año la tendencia del premio era a la baja, y en julio se situaba ya en torno al 22 por $100^{63}$. Como era lógico, Spinola, por lo general muy bien informado, estaba defendiendo los intereses de la Real Hacienda, adelantándose ligeramente a la tendencia del mercado. Sabía que el tiempo jugaba a su favor y que cualquier reticencia a aceptar su oferta iba en perjuicio del interesado en el cambio.

Otro ejemplo de este tipo de gestiones fue el pago en 1639 de los 2.000 ducados de plata que la Real Hacienda debía enviar a los Santos Lugares de Jerusalén. El rey Felipe III había donado una renta de juro para el sustento de los religiosos que los asistían y cuidaban. Ahora la renta se cobraba en vellón, pero el giro a Jerusalén debía seguir haciéndose en plata. Bartolomé Spinola se hizo cargo de reducir esa suma a metal precioso con un premio máximo del 28 por 100 cuando por entonces el premio en el mercado corría a un 38 por $100^{64}$. Ese coste corrió a cargo de la Real Hacienda sobre el dinero de la factoría general ${ }^{65}$.

Era importante, pues, dotar al Factor General del metal precioso necesario con el que pudiese llevar a cabo todos los negocios que la Real Hacienda le fuese confiando. Por esta razón, Spinola tuvo acceso al dinero disponible en la receptoría del Consejo de Hacienda o en otras oficinas oficiales ${ }^{66}$ y gozó de ciertos privilegios para hacerse con el que circulaba libremente en el mercado. Uno de los lugares donde el Factor General solía conseguir plata a cambio de entregar vellón era el Depositario General de la Corte ${ }^{67}$. Los lugares donde encontró metales preciosos no fueron

${ }^{63}$ AGS CJH, leg. 674. Memorial, 18-7-1630.

of Serrano Mangas (1996), p. 66.

${ }^{65}$ Según los datos de Serrano Mangas (1996), p. 75

66 Para el trueque Bartolomé Spinola se sirvió de la Casa de Reducción del vellón que funcionaba en Madrid. Bartolomé entregó en ella $750.000 \mathrm{mrs}$. de vellón, más otros $210.000 \mathrm{mrs}$. por el premio de la reducción, y recibió de la Casa los 2.000 ducados de plata. El Factor recuperó los 2.000 ducados de vellón de la persona que cobraba la renta de los Santos Lugares y que se encargaría de remitir el dinero, pero los $210.000 \mathrm{mrs}$ del premio se pagaron con los fondos de la factoría que tenía a su cargo. AHPNM, protocolo 4525, fol. 26. Carta de pago, 14-1-1639.

67 AHPNM, protocolo 4513, fol. 329. Otro de los lugares para efectuar cambios de moneda fue el Receptor de la Junta de Armadas.

${ }^{68}$ En abril de 1628 Spinola se encargó de pagar la redención de un censo al maestro de obras y alarife de Madrid. En su día éste había entregado 700 ducados de plata doble al Depositario General. Ahora se le entregaba esa misma cantidad en vellón, aplicándole una reducción del 52 por 100. AHPNM, protocolo 4513, fol. 257. Carta de pago, 7-4-1628. Recibió de Bartolomé Spinola 11.704 reales de vellón. La orden de reducción se la dio 
solamente organismos oficiales. También practicó cambios con los mercaderes y hombres de negocios de Madrid ${ }^{68}$.

Cuando en 1641 la Real Hacienda empezó a encontrar realmente dificultades para disponer de plata decidió asegurarse una parte de la que recibían los arrendadores de rentas reales en el cumplimiento de su oficio. Por eso encargó al Factor General que negociase con todos ellos un compromiso formal para proporcionar regularmente plata a las arcas reales, como una más de las obligaciones de su arrendamiento ${ }^{69}$. Todo el peso de la negociación quedó en sus manos, incluso el de establecer el premio de la plata cuando fue preciso ${ }^{70}$. La fórmula empleada consistió en pagar la cuarta parte del valor de la renta en plata y el resto en vellón, sin premio alguno. No todos los interesados estuvieron de acuerdo. Hubo algún arrendador, como fue el caso de Duarte Coronel Enríquez, arrendador de los puertos secos y almojarifazgos del mar de Castilla, que salieron perjudicados $^{71}$. El Consejo de Hacienda fue informado puntualmente de las gestiones según se fuera resolviendo.

Con anterioridad a esta exigencia generalizada por parte de la Real Hacienda hacia sus arrendadores, Spinola ya había concertado acuerdos parciales con algunos de ellos para que le facilitasen plata. Esos acuerdos habían sido posibles gracias a su influencia en el Consejo de Hacienda en la concesión de los arrendamientos. Un ejemplo fue el que estableció con Simón de Fonseca Piña, recaudador del nuevo derecho sobre la exportación de lanas. Simón se comprometió a rebajarle el precio del cambio y a suministrarle plata durante todo el año, cediéndole el cobro de las obligaciones libradas por los que debían pagar ese impuesto. En el caso

el Licenciado Pantoja, teniente corregidor de Madrid. El Factor General se hizo con la plata a un precio muy bajo, porque en el mercado corría entonces a un 71 por 100 . Serrano Mangas (1996), p. 64.

${ }_{69}$ AHPNM, protocolo 4527.

${ }^{70}$ AGS CJH, leg. 828. Memorial de Bartolomé Spinola, 27-1*1641. El Factor General llevó toda la gestión por correspondencia, pues en ningún momento abandonó Madrid, como había hecho años atrás para negociar varios asuntos en Sevilla.

71 AGS CJH, leg. 828. Memorial de Duarte Brandón, 22-1-1641. Con Duarte Brandón, arrendador de los almojarifazgos, se computó la plata en términos de vellón, estableciendo un premio del 34 por 100. Este arrendador se comprometió a ir entregando la plata en Sevilla en pagas mensuales, desde finales de abril a diciembre. Los años que invernasen las flotas se debía suspender lo que correspondía al precio del almojarifazgo de Indias en los últimos dos meses, hasta que llegasen los galeones.

72 AGS CJH, leg. 828. Consulta del Consejo de Hacienda, 4-2-1641. Su queja era que debido a la nueva exigencia, la lana saldría por los almojarifazgos, en lugar de contribuir en los distritos de sus rentas, con grave perjuicio para la recaudación. 
de que se retrasase el pago de alguna de las libranzas, Spinola tendría derecho a un 8 por 100 de interés anual ${ }^{72}$. Por otra parte, el cambio de vellón se haría un 5 por 100 más barato que el premio fijado anualmente por la Real Hacienda en la negociación de las Provisiones Generales.

En muchas ocasiones Bartolomé Spinola no dejó de mostrar su disconformidad hacia la política monetaria seguida por la Corona. Una de las recomendaciones que repitió con más insistencia fue la de abandonar el tipo de cambio fijo establecido oficialmente como medio para atajar la inflación del vellón. Ese premio oficial estaba muy alejado del valor real y era una de las causas de las perturbaciones del mercado. En su opinión, el encarecimiento de los premios y el daño que eso infligía al sistema monetario procedía precisamente de la rigidez con la que se había regulado el cambio. La obligación de trocar dinero sólo en las Diputaciones para el consumo del vellón cuando éstas no disponían de plata para hacerlo estaba envenenando cualquier operación donde fuesen imprescindibles los metales preciosos. En su opinión, se debía dar libertad para trocar al precio que marcase el mercado, aunque hubiese que hacerlo a precios mucho más altos que los fijados en las pragmáticas. Quizá se podía seguir manteniendo la obligación de pagar en las Diputaciones la tasa establecida para el trueque, pero lo verdaderamente grave era pretender controlar de forma rígida los cambios ${ }^{73}$.

\section{LA RED FINANCIERA EUROPEA DEL FACTOR GENERAL}

Una de las partes más importantes del éxito de su gestión financiera como Factor General del rey fue contar con una extensa red de colaboradores y correspondientes en las principales plazas europeas. Esa red le permitía tanto hacerse cargo de efectuar pagos como cobrar cualquier suma en nombre de la Real Hacienda. Una red de personas de confianza y al mismo tiempo suficientemente solventes como para no poner en entredicho el prestigio del Factor General.

No existía ninguna relación entre la administración real y los colaboradores del Factor General. La Real Hacienda incorporó a su servicio a Bartolomé Spinola, quien; como ya hemos señalado, abandonó sus negocios privados para dedicarse por entero a su nuevo cargo, pero no estableció ningún lazo permanente con los colaboradores del banquero genovés. El

73 AHPNM, protocolo 4527, fol. 48. Foder, 28-1-1641.

74 AGS CJH, leg. 654. Consulta, 26-5-1628. 
Factor General debía encargarse de reclutar y mantener a sus propios ayudantes, desde los más íntimos hasta las personas que trabajarían en negocios temporales. El estudio de esta red es otro amplio y apasionante campo para desentrañar el funcionamiento de las finanzas privadas en el siglo xvI, y más en concreto el entramado financiero de los genoveses en Europa.

A la hora de estudiar las conexiones de Bartolomé Spinola encontramos, según el tipo de colaboración establecido, compañías, procuradores y colaboradores. Términos poco definidos y en muchas ocasiones casi equivalentes. Las compañías de negocios con las que siguió trabajando eran similares a la que él mismo había constituido en Madrid con su socio Juan Andrea. Algunas de las cuales ya han sido nombradas al estudiar sus actividades como banquero privado. Normalmente esas compañías recibían poderes del Factor para realizar pagos en su nombre, cobrar dinero, protestar letras, hacer requerimientos, embargar bienes y finiquitar cuentas.

El que en una plaza se establecieran habitualmente relaciones con un agente y su compañía de negocios no implicaba una relación de exclusividad. Podía existir un procurador habitual y, al mismo tiempo, encargarse otras personas de acciones concretas. El caso más significativo es Sevilla, donde Bartolomé contaba con muchos y muy variados colaboradores. Unos encargados de cobrar consignaciones, como los que recibían en su nombre los metales preciosos de la Casa de la Contratación; otros administraban alguna de las rentas cuyo cobro tenía asignado el Factor ${ }^{74}$, y de forma esporádica también contaba con ciertas personas para encargos de menor importancia. Sin duda la distancia de Madrid y las características propias de cada plaza de negocios impuso las posibilidades reales de diversificar el riesgo, confiando en una sola persona o en varias.

\section{LAS TRANSFERENCIAS DEL DINERO EN METÁLICO}

Cuando la Real Hacienda necesitaba que una cantidad de dinero estuviese $\sin$ fallos ni retrasos en cualquier punto de la geografía europea el mejor medio era siempre confiar esa gestión al Factor General. Son muchos y muy diversos los ejemplos que a este respecto se pueden poner tanto

${ }^{75}$ Para cobrar la media annata de los juros en la alcabala de Sevilla, Bartolomé Spinola contó en 1640 con Pedro Francisco Spinola, hermano de Octavio Spinola, un conocido agente genovés de Sevilla. Esa gestión quedó vinculada a la negociación con el mismo Pedro Francisco de un asiento de 150.000 ducados de vellón, cuya consignación era precisamente el fruto de la recaudación de la media annata. 


\section{CUADRO 2}

Compañias y agentes colaboradores del Factor General del Rey

\begin{tabular}{ll}
\hline & \multicolumn{1}{c}{ Ciudad } \\
\hline Amberes & $\begin{array}{l}\text { Joanetin de Negro } \\
\text { Ansaldo Lercaro }\end{array}$ \\
\hline Milán & $\begin{array}{l}\text { Julio y Jorge Sanguineto } \\
\text { Claudio Spinola }\end{array}$ \\
\hline Roma & $\begin{array}{l}\text { Bautista Serra } \\
\text { Octavio Costa }\end{array}$ \\
\hline Nápoles & $\begin{array}{l}\text { Juan Bautista Pinelo } \\
\text { Cornelio Spinola } \\
\text { Tomás Pinelo }\end{array}$ \\
\hline Barcelona & Jacome y Juan Bautista Negro \\
\hline Sevilla & Juan Bautista Ponzón \\
& $\begin{array}{l}\text { Antonioto Spinola y Alexandro } \\
\text { Grimaldo }\end{array}$ \\
\hline
\end{tabular}

en la gestión del dinero en efectivo como en el giro efectuado utilizando papel. En la propia Península Ibérica la Junta de Galeras solicitó en 1630 el envío urgente de 110.000 reales a Cartagena para la provisión urgente de la escuadra de Nápoles. Antes de que la propia Junta se encargase de enviar el dinero el Consejo de Hacienda prefirió confiar en la experiencia de Bartolomé Spinola, pues en su opinión lo haría «con la puntualidad y beneficio que suele» ${ }^{75}$, ya fuese en metálico o a través de letras.

Este tipo de servicios no fueron realizados exclusivamente en Castilla. En la manipulación del dinero al contado lo más frecuente y habitual fue la transferencia a Italia. Una de las operaciones de mayor envergadura llevadas a cabo por Bartolomé Spinola fue la transferencia de 1.500 .000 ducados en plata y oro que Felipe IV ordenó situar en Milán en $1629^{76}$. Bartolomé Spinola debía recibir un total de 1.310.000 ducados de la Casa de la Contratación y de los administradores de la avería. Esa suma iba destinada a sostener el ejército que combatiría en el norte de Italia al

76 AGS CJH, leg. 665-19-4. Consulta, 26-3-1630.

7 AGS CJH, leg. 656-1-15. Consulta, 8-6-1629. 
mando del general Ambrosio Spinola. De hecho, junto con el dinero se envió también un refuerzo de 26.000 infantes y 4.000 jinetes. Esa suma se reunió incautando un millón de ducados del dinero registrado por los particulares en las flotas americanas que llegaron a Sevilla en el mes de abril. Además se decidió que los administradores de la avería contribuyesen con una aportación extraordinaria, pues eran los únicos que disponían de liquidez en esos momentos. Para compensarles se elevó en un 5 por 100 la contribución del registro de las flotas a la avería ${ }^{77}$. Al final sólo se pudieron reunir 1.240.000 ducados. El Consejo encargó al Factor General que buscase un seguro para cubrir «el riesgo de la mar» en el transporte de una suma tan elevada. La compañía «Juan Lucas y Gregorio Spinola» se encargó de buscar aseguradores en Génova, pero sólo encontraron pólizas para cubrir un millón, y además con una prima del 14 por 100 , demasiado alta para la Real Hacienda. Ante la dificultad para encontrar más aseguradores y más baratos Spinola convenció finalmente al Consejo de Hacienda para enviar el dinero sin seguro ${ }^{78}$.

En 1638 se le ordenó la recaudación de las medias annatas de los juros de naturales y extranjeros. Su trabajo consistía en cobrar este impuesto a los recaudadores de las rentas donde estuviesen situados los títulos de deuda. Para llevarlo a cabo se le nombró juez particular de su Majestad para esta cobranza, entregándole los poderes necesarios para hacerlos valer ante los tesoreros y arrendadores de las rentas reales ${ }^{79}$. $\mathrm{Al}$ año siguiente Bartolomé Spinola fue nombrado juez particular para cobrar las annatas, medias annatas y cuartas partes de las renta y estanco de la pimienta, cuyos tesoreros eran Fernando Manuel y Francisco Méndez Correa ${ }^{80}$. Spinola tuvo especialmente a su cargo el cobro de los derechos situados sobre las rentas de Madrid y Sevilla. Según el Consejo de Hacienda, su gestión había supuesto un gran beneficio para las arcas reales, porque ambos lugares eran los más importantes en cuanto a volumen recaudado. Las dos ciudades suponían más de la mitad de ese ingreso. Una vez más la experiencia había demostrado la buena gestión del Factor, pues mientras aquí se cobraba con puntualidad, en otros lugares se sucedían las denuncias por la quiebra de tesoreros y arrendadores, con gran perjuicio para las arcas reales ${ }^{81}$.

78 Álvarez Nogal (1997a), pp. 196-198.

79 AGS CJH, leg. 656. Consultas, 19-6-1629 y 4-7-1629. Bartolomé Spinola decía que si el dinero fuese suyo no lo aseguraría y correría el riesgo, pues las galeras en las que iba a ser transportado a Génova eran muy buenas.

${ }^{80}$ AHPNM, protocolo 4525, fol. 174. Poder, 4-3-1639.

81 AHPNM, protocolo 4525, fol. 736. Escritura de obligación, 16-8-1639.

82 AGS CJH, leg. 828. Minuta, 29-6-1641. 
Al final de su vida se le encargó la superintendencia de la fábrica y labor de la moneda, en un intento desesperado por atajar los problemas monetarios, quizá coincidiendo con uno de los momentos más críticos de la Real Hacienda ${ }^{82}$. Poco pudo hacer Bartolomé en este aspecto. Sus días terminaban, mientras la solución del problema monetario no fue precisamente una cuestión fácil de resolver.

\section{CONCLUSIONES}

El estudio detallado de las actividades desarrolladas por Bartolomé Spinola como Factor General del rey supone adentrarse en los problemas económicos y financieros de la Monarquía Hispánica durante la primera mitad del reinado de Felipe IV. Eso pone de manifiesto la complejidad de las funciones que asumió y la importancia de su experiencia, especialmente en la negociación del crédito y en la solución de los complejos problemas monetarios.

La singularidad derivada de la incorporación de un banquero privado al sistema financiero de la Monarquía supuso dinamizar la capacidad crediticia de la Real Hacienda y reportó un gran beneficio para las arcas reales. El éxito de esta iniciativa no fue sólo consecuencia del rigor con el que Spinola llevó a cabo la gestión de la factoría, gracias a su inteligencia y valía personal, sino sobre todo por su agilidad en la toma de decisiones y la independencia que se le otorgó para cumplir ese objetivo.

Cuando Felipe IV decidió resucitar la figura del Factor General la Real Hacienda castellana requería urgentemente una persona con prestigio y experiencia, cuya autorizada opinión orientase las decisiones del Consejo de Hacienda en un momento en el que los recursos empezaban a ser insuficientes. Además Bartolomé Spinola se encargó de elevar al rey informes muy interesantes sobre la situación de las ferias de pagos europeas, la realidad económica y financiera castellana, así como los remedios más convenientes para resolver algunos de sus problemas. A diferencia de los consejos que los arbitristas hicieron llegar al Consejo, la influencia del Factor General le permitió que muchas de sus sugerencias se pusiesen en práctica. En muchas ocasiones no fue el Factor, sino el propio Consejo el que solicitó su opinión antes de concertar un asiento, establecer un nuevo impuesto o discutir sobre la conveniencia de realizar una determinada provisión en el extranjero.

${ }^{* 3}$ AGS CJH, leg. 852. Consulta, 15-1-1643. 
La actividad global desarrollada por Bartolomé Spinola como Factor General no es comparable, ni en dimensiones ni en trascendencia, a la llevada a cabo por cualquier otro banquero del XvII. De hecho, tras su muerte en 1644, a pesar de los intentos de la Real Hacienda por encontrar un sustituto, no hubo quien ocupase su lugar. El fracaso en el que terminó el nombramiento de Juan Esteban Invrea sólo pudo ser reparado en 1650 con su relevo por Andrea Pichinotti. Sin embargo, a pesar de la importancia que desde entonces sin duda tuvo este banquero, ni las dimensiones de su negocio, ni la coyuntura económica del final del reinado de Felipe IV, le permitieron convertirse en un Factor General equiparable a Bartolomé Spinola.

\section{BIBLIOGRAFÍA}

Álvarez Nogal, C. (1997a): El crédito de la Monarquía Hispánica durante el reinado de Felipe IV, Valladolid, Junta de Castilla y León.

- (1997b): Los banqueros de Felipe IV y los metales preciosos americanos (1621-1665), Madrid, Banco de España.

- (en prensa) «EI negocio del seguro a comienzos del xvi en Génova, Sevilla y Venecia. La compañía "De Marini-Spinola" a través de su contabilidad". Artolu, Miguel (1982): La Hacienda del Antiguo Régimen, Madrid, Alianza.

Braudel, F. (1977): «Génes au début du XVIIe siècle», en Fatti e idee di storia economica nei secoli XII-XX. Studi dedicati a Franco Borlandi. Bolonia, Il Mulino, pp. $457-479$.

CARANDE, Ramón (1945): «El destino de los tesoros ultramarinos en la hacienda del Emperador (1520-56)», Moneda y Crédito, núm. 13, Madrid, pp. 15-36.

- (1965-67): Carlos V y sus banqueros, Madrid, Sociedad de Estudios y Publicaciones.

Gentil da Silva, J. (1969): Banque et crédit en Italie au XVIle siècle, París, C. Klineksiek.

Dominguez OrTiz, Antonio (1956): «Las remesas americanas y la política exterior de Felipe IV», Anuario de Estudios Americanos, núm. 13, Madrid, pp. 311-383.

- (1960): Política y Hacienda de Felipe IV, Madrid, Edit. de Derecho Financiero.

DORIA, G. (1977): «Un quadriennio critico: 1575-1578. Contrasti e nuovi orientamenti nella società genovese nel quadro della crisi finanziaria spagnola», en Fatti e idee di storia economica nei secoli XII.XX. Studi dedicati a Franco Borlandi, Bolonia, Il Mulino, pp. 377.394.

- (1978): «Consideraciones sobre las actividades de un "factor-cambista" genovés al servicio de la Corona española», en Otazu, A. (ed.). Dinero y Crédito (siglos XVI al XIX), Madrid, Moneda y Crédito, pp. 279-293.

Elliotr, J. H. (1991): El Conde-Duque de Olivares, Barcelona, Crítica.

FELLONI, G. (1971): Gli investimenti finanziari genovesi in Europa tra il Seicento e la Restaurazione, Milán, Giuffrè. 
- (1978): «Asientos, juros y ferias de cambio desde el observatorio genovés (1541-1675)», en OTAZU, A. (ed.), Dinero y Crédito (siglos XVI al XIX), Madrid, Moneda y Crédito, pp. 335-359.

Garzón Pareja, M. (1980): La Hacienda de Carlos II, Madrid, Instituto de Estudios Fiscales.

Gelabert, J. E. (1997): La bolsa del rey. Rey, reino y fisco en Castilla (1598-1648), Barcelona, Crítica.

Ghilino, S. (1996): Un banchiere del '600: Stefano Balbi. Affari di Stato e fiere dei cambi, Genova, Università di Genova.

Hernández Esteve, E. (1983): Creación del Consejo de Hacienda de Castilla (1523-1525), Madrid, Banco de España.

- (1984): «Las cuentas de Fernán López del Campo, primer Factor General de Felipe II para los reinos de España (1556-1560)», Hacienda Pública Española, núm. 87, 1984, pp. 85.105.

- (1986): Establecimiento de la partida doble en las cuentas centrales de la Real Hacienda de Castilla (1592), Madrid, Banco de España.

Pellicer, J. (1991): Avisos bistóricos, Madrid.

RipIA, Juan de (1768): Práctica de la administración y cobranza de las rentas reales y visita de los ministros que se ocupan en ellas, Madrid.

Ruiz Martin, Felipe (1965): «Un expediente financiero entre 1560 y 1575. La Hacienda de Felipe II y la Casa de la Contratación de Sevilla», Moneda y Crédito, núm. 92, Madrid, pp. 3-58.

- (1970): «La banca en España hasta 1782», en W.AA., El Banco de España. Una bistoria económica, Madrid, Banco de España, pp. 1-196.

- (1990): Las Finanzas de la Monarquia Hispánica en tiempos de Felipe IV (1621-1665), Madrid, Real Academia de la Historia.

SánCHez BelÉn, J. A. (1996): La política fiscal en Castilla durante el reinado de Carlos II, Madrid, Siglo XXI Editores.

SANZ AYÁN, Carmen (1988): Los banqueros de Carlos II, Valladolid, Universidad de Valladolid.

Serrano Mangas, F. (1996): Vellón y metales preciosos en la Corte del rey de España (1618-1668), Madrid, Banco de España.

Tinoco Rublales, S. (1981): «Mercaderes, banqueros y bancos públicos. Aproximación a la problemática del trato y la banca en la Sevilla del siglo XVI», Revista de Historia Moderna, núm. 1, Barcelona, pp. 347-353.

Trasselli, C. (1972): «Finanza genovese e pagamenti esteri 1629-1643», Rivista storica italiana, núm. 84 , pp. 978-987.

UlloA, Modesto (1977): La Hacienda Real de Castilla en el reinado de Felipe II, Madrid, FUE. 